\title{
JOGO DE DOIS NÍVEIS VOLTADO AO ELEITORADO: UMA ANÁLISE DA POLÍTICA EXTERNA BOLSONARISTA
}

\author{
TWO-LEVEL GAMES ELECTORATE ORIENTED: AN ANALYSIS OF BOLSONARIAN \\ FOREIGN POLICY
}

\author{
Giorgio Romano Schutte ${ }^{1}$ \\ Bruno Castro Dias da Fonseca² \\ Gabriel Santos Carneiro ${ }^{3}$
}

\begin{abstract}
Resumo
A política externa do governo Jair Bolsonaro efetivamente praticada no primeiro ano de governo reflete uma disputa entre uma ala que preza por uma condução economicamente pragmática da Política Externa Brasileira (PEB), considerando os interesses econômicos e comerciais envolvidos, e uma "ala olavista", de orientação ideológica conservadora. Neste artigo, lança-se mão do conceito de "Jogos de Dois Níveis", de Robert Putnam, para analisar essa dinâmica. A tese defendida é que há uma tentativa de usar a Política Externa pela ala ideológica para dialogar com sua base eleitoral. Assim, serão analisados alguns dos principais eventos da PEB no período. Enfatiza-se a incoerência estrutural que surge da influência de ambas as alas e sistematiza-se os benefícios e prejuízos das posturas tomadas, contribuindo também para, com a literatura de análise da política externa, vislumbrar quais seriam os contornos, rupturas e continuidades da inserção internacional brasileira sob o governo Bolsonaro.
\end{abstract}

Palavras-Chave: Análise de política externa; Eleitorado; Política Externa Brasileira; Jair Bolsonaro.

\begin{abstract}
Foreign policy effectively implemented by the Jair Bolsonaro administration in his first year in office reflects a dispute between a wing which stands for the economic pragmatic conduction of the Brazil's foreign policy, reflecting economic and commercial interest, and an "olavista wing", with an ideological and new conservative orientation. To analyze this dynamics, we will use the concept of "two-level games" from Robert Putnam. The basic argument is that Bolsonaros's Foreign Policy is used to mobilize its electoral base. For this, an analysis is made of the main events reflecting Brazil's foreign policy in this period. By this, the structural incoherence as an outcome of the influence of both wings is highlighted and the benefits and losses of the stances taken exposed. Therefore, the article pretends to contribute to the literature on foreign policy analysis, focusing on the outlines, disruptions and continuities of Brazil's international insertion under Bolsonaro's government.
\end{abstract}

\footnotetext{
${ }^{1}$ Professor-Doutor em Relações Internacionais e Economia da Universidade Federal do ABC. Membro do corpo docente dos Programas de Pós-Graduação em Economia Política Mundial (EPM) e de Relações Internacionais (PRI) da Universidade Federal do ABC (UFABC). Coordenador do Observatório da Política Externa e da Inserção Internacional do Brasil (OPEB). E-mail: giorgio.romano@ufabc.edu.br. ORCID: https://orcid.org/0000-0002-5225-469X.

${ }^{2}$ Bacharel em Relações Internacionais e Ciências \& Humanidades pela Universidade Federal do ABC. Mestrando em Sociologia na Universidade de São Paulo. Membro do Observatório de Política Externa e Inserção Internacional do Brasil (OPEB). E-mail: bruno.castro@aluno.ufabc.edu.br. ORCID: https://orcid.org/0000-0002-4391-2646.

${ }^{3}$ Bacharel em Ciências \& Humanidades pela Universidade Federal do ABC. Cursa bacharelado em Relações Internacionais e bacharelado em Ciências Econômicas na mesma instituição. Membro do Observatório de Política Externa e Inserção Internacional do Brasil (OPEB). E-mail: gabriel.carneiro@aluno.ufabc.edu.br. ORCID: https://orcid.org/0000-0002-1321-7183.
} 
Keywords: Foreign policy analysis; Electorate; Brazilian Foreign Policy; Jair Bolsonaro.

\section{INTRODUÇÃO}

Qualquer estudo de análise de política externa que parta de uma análise estritamente doméstica ou estritamente internacional será incapaz de compreender por completo os determinantes e os objetivos da política externa de uma nação. Logo, é imprescindível uma análise em "dois níveis", que objetive elucidar os entrelaçamentos entre a política doméstica e a política internacional. Nesse sentido, abordagens estadocêntricas ${ }^{4}$ de análise de política externa se mostraram insuficientes para captar a dinâmica da luta política nacional - que envolve partidos, classes sociais e grupos de interesses econômicos e não-econômicos - e a sua influência na política externa dos Estados. Assim, de modo geral, enquanto que, no nível nacional, os grupos domésticos, representados nas diferentes alas do governo, pressionam o governo a adotar políticas favoráveis a seus interesses, no nível internacional, os governos buscam satisfazer as pressões domésticas ao mesmo tempo em que tentam minimizar quaisquer consequências negativas no tabuleiro internacional. No que diz respeito ao presente artigo, pretende-se destacar que a atuação internacional de governos também pode ser motivada pelo objetivo de influenciar o próprio jogo da luta política nacional (PUTNAM, 1988).

A forma como um Estado promove a sua inserção internacional, a saber, sua política externa, almeja representar os interesses dos grupos participantes do governo (TARGA, 2017). Devido à relevância que grandes grupos econômicos geralmente possuem na política nacional, tais interesses costumam estar presentes no governo, tendendo a serem super-representados na política externa. No caso do governo Jair Messias Bolsonaro ${ }^{5}$, verifica-se que os interesses comerciais desses grupos estão assentados principalmente entre os ministérios da Economia, da Agricultura, Pecuária e Abastecimento (MAPA) e o de Minas e Energia. Neste aspecto, não houve alteração com relação à realidade em governos anteriores. Já o Ministério da Defesa, por sua vez, tanto quanto o vice-presidente da República, representam, no governo, os interesses da corporação militar, que, historicamente, tem apoiado o anseio das elites econômicas nacionais pelo pragmatismo econômico ${ }^{6}$ em matéria de política externa.

\footnotetext{
${ }^{4}$ Katzenstein (1976) afirma acreditar que a falta de atenção às dinâmicas da política doméstica no campo de estudo das de relações internacionais é fruto de uma presumida similaridade e homogeneidade presente nos estudos dos Estados industriais mais desenvolvidos.

${ }^{5}$ Jair Messias Bolsonaro é capitão reformado do exército, deputado por seis mandatos e atual presidente do Brasil, eleito em 2018.

${ }^{6} \mathrm{Na}$ historiografia da política externa brasileira, o uso do termo "pragmático" foi concedido em episódios da inserção internacional brasileira em que o Ministério das Relações Internacionais prezou por relações que beneficiassem o Brasil a despeito das divergências ideológicas entre os países - com o caso clássico
} 
A novidade que se observa é a presença no governo de uma ala com força política que apresenta visões e atitudes potencialmente conflitivas com uma condução econômicopragmática da política externa - logo, com os interesses dos grupos econômicos-comerciais que sustentam o mesmo governo. Os principais integrantes dessa ala, a saber, Ernesto Araújo ${ }^{7}$, Eduardo Bolsonaro ${ }^{8}$, o próprio presidente e seu assessor para política internacional, Filipe Martins $^{9}$, são inspirados na filosofia política de Olavo de Carvalho ${ }^{10}$.

Essa filiação teórica justifica que, para fins analíticos, tal conjunto de atores seja aglutinado sob a denominação de "ala olavista". A forma de inserção internacional do Brasil advogada por este grupo diverge, por sua vez, diretamente dos interesses das elites econômicas. Assim foi quando, por exemplo, cogitou-se a mudança da embaixada brasileira em Israel para Jerusalém, ou quando a mesma ala adotou postura discursiva hostil às parcerias econômicas e políticas com a China, ou ainda quando respaldou, indiretamente, a ideia de executar intervenções políticas e militares na Venezuela.

Por consequência, criou-se uma inédita tensão com o pragmatismo econômico no que se refere ao discurso de política externa, na medida em que aspira subordinar o conteúdo econômico da inserção internacional ao sentido político-ideológico da mesma. É equivocado admitir, contudo, que o discurso da ala olavista é despido de racionalidade, um ato cínico conduzido aleatoriamente, ou mero fruto de devaneios alheios à realidade. Pode-se identificar, no âmago da condução dessa política externa polêmica, uma aposta política que, principalmente durante as eleições, mostrou-se profícua, na medida em que corresponde aos anseios e às aspirações ideológicas e culturais de parte importante do seu eleitorado. Quer dizer: a ideologização da política externa foi construída estrategicamente por Bolsonaro e pela ala olavista ao longo dos últimos anos e integrou a campanha eleitoral. Os ganhos perseguidos pela política externa praticada por essa ala não são primariamente econômicos-comerciais, mas sim de natureza simbólica, visando mobilizar a base eleitoral do presidente.

do conceito utilizado para descrever a PEB do governo Geisel, o "pragmatismo ecumênico e responsável". Assim, "pragmatismo" se refere tanto às relações econômicas quanto políticas. Contudo, no presente artigo, com "pragmatismo econômico" - e sinônimos -, nos referiremos a relações bilaterais voltadas apenas para ganhos econômicos.

${ }^{7}$ Ernesto Araújo é diplomata, atual Ministro das Relações Exteriores do Brasil e um autoproclamado aluno de Olavo de Carvalho.

${ }^{8}$ Eduardo Bolsonaro é deputado federal e filho do atual presidente Jair Messias Bolsonaro.

${ }^{9}$ Filipe Martins é Assessor para Assuntos Internacionais do Presidente da República autoproclamado aluno de Olavo de Carvalho.

${ }^{10}$ Olavo Luiz Pimentel de Carvalho é um intelectual brasileiro. 
Sendo assim, o presente artigo ambiciona discutir a forma como o governo Bolsonaro mobiliza a política externa para fortalecer sua posição na política doméstica ${ }^{11}$. Para tanto, num primeiro momento, apresentaremos uma leitura "adaptada" da teoria do jogo de dois níveis de Putnam e, em sequência, será discutida a composição do eleitorado de Jair Messias Bolsonaro e sua relação com a concepção da política internacional da "ala olavista". Em seguida, mobilizamos alguns dos episódios da política externa brasileira de 2019 e enfatizamos como o plano internacional ancorou discursos para favorecer setores do eleitorado de Bolsonaro. $\mathrm{Na}$ conclusão, debatemos a popularização da política externa, seus usos eleitorais e os benefícios de uma análise de política externa que leve em conta essa dinâmica.

A metodologia que ensejou o presente trabalho é dividida em dois momentos. No primeiro, um mapeamento das notícias acerca dos episódios da política externa brasileira ocorridos entre janeiro de 2019 e outubro do mesmo ano. Em seguida, essa base empírica foi analisada, caso a caso, pela perspectiva teórica Jogo de Dois Níveis, com o intuito de avaliar se a ala olavista de fato mobilizou o plano internacional para favorecer uma parcela dos eleitores do Bolsonaro e com isso gerando uma permanente incoerência na condução da política externa.

\section{UMA ADAPTAÇÃO DA TEORIA DO JOGO DE DOIS NÍVEIS}

O campo de estudos de análise de política externa é tradicionalmente marcado pelo embate teórico entre os que defendem que a política doméstica determina as relações internacionais e os que afirmam o inverso. Em artigo publicado em 1988 denominado Diplomacy and Domestic Politics: The Logic of the Two-Level Games, Robert Putnam, buscando compatibilizar as diferentes visões, elabora uma sistematização teórica sobre a forma como a política internacional e a política doméstica interagem e determinam as negociações internacionais. Tal perspectiva, portanto, volta-se ao objetivo de investigar em quais situações há predominância do nível doméstico, e em quais situações o nível internacional é preponderante. Além disso, também são analisadas as formas pelas quais cada nível é capaz de influenciar o outro.

Para o autor, a luta política das negociações internacionais pode ser concebida como um jogo de dois níveis. O primeiro consiste no âmbito nacional, caracterizado pela presença de grupos domésticos que se aglutinam em coalizões e perseguem seus interesses próprios pressionando o governo nacional. O segundo, por sua vez, seria a esfera da política internacional,

\footnotetext{
${ }^{11} \mathrm{O}$ presente trabalho não ambiciona discutir as rupturas e continuidades da política externa de Bolsonaro em relação às tradições da $\mathrm{PEB}$, embora o material empírico mobilizado permita contribuições para esse debate.
} 
marcado pela tentativa dos governos de satisfazerem as demandas de certos grupos domésticos ao mesmo tempo em que buscam minimizar as adversidades da disputa de poder desigual da competição interestatal. Neste contexto, o líder político de uma nação é visto como um "jogador" que joga nos dois planos, atuando no nível internacional, ao lado de diplomatas e assessores nacionais e estrangeiros, de outros líderes de Estado e de diversos grupos que compõem a sociedade civil internacional; e no nível doméstico, rodeado por partidos, classes sociais e grupos de interesses econômicos e não-econômicos (PUTNAM, 1988).

Torna-se evidente, assim, a imensa complexidade do jogo de dois níveis. Os jogadores de ambos os níveis estão sempre sujeitos a mudanças em qualquer um dos níveis, de forma que, para aumentarem suas chances de terem seus objetivos assegurados, os jogadores devem estar constantemente atentos às movimentações tanto no nível doméstico quanto no internacional. Para além disso, a capacidade dos negociadores também consiste em uma variável essencial na definição dos jogos (nível individual), sendo um exímio negociador capaz de influenciar altamente as negociações em função de seus interesses (PUTNAM, 1988).

Putnam (1988), ao longo de sua obra, estava interessado principalmente em compreender como os jogos de dois níveis explicam as possibilidades de ratificação de tratados e acordos internacionais, cunhando, inclusive, o conceito de "conjunto de vitórias" (win-sets) para tal análise. A correlação comprovada em sua teoria entre os níveis doméstico e internacional permite adaptar sua perspectiva para a análise de outros casos que envolvem o entrelaçamento da política externa com a doméstica, sem que necessariamente haja uma negociação internacional de fato envolvida.

Vale ressaltar que o autor já deixara em aberto a possibilidade de politização interna da atuação internacional de um país ao afirmar que a prática política e o conflito entre grupos domésticos variam de acordo com a politização do assunto: quanto maior a politização ${ }^{12}$ interna da política externa ao afirmar que a atuação política e o conflito entre os grupos domésticos variam de acordo com a politização do assunto, sendo que quanto maior a politização, maior a complexidade de interesses envolvidos e menor o "grupo de vitórias" que possibilita a ratificação de um acordo internacional.

O modelo de jogo de dois níveis de Putnam (1988), entretanto, não abrange a discussão sobre o impacto de ideias na formação da política externa de uma nação. Conforme indicam Keohane e Goldstein (1993), grande parte da literatura realista e institucionalista liberal do campo de estudos das relações internacionais relegam às ideias um papel secundário em seus modelos de análise e de compreensão do mundo. Esses autores defendem que as ideias são fator

\footnotetext{
12 Putnam (1988) em seu texto original não apresentou nenhuma definição para o conceito de "politicization". O presente artigo compreende este conceito como a dinâmica em que diferentes grupos de interesse tornam um tema ou assunto objeto de disputa política.
} 
determinante da política, uma vez que moldam e definem as estratégias que os atores adotam para perseguir seus objetivos. Tais metas são selecionadas com base em diferentes princípios morais e éticos, contidos em diferentes visões de mundo coexistentes na sociedade.

Em diferente perspectiva, Milner (1997) busca combinar a visão dos jogos de dois níveis com a proposição de que ideias, interesses e preferências moldam as decisões políticas. Segundo a autora, tais interesses consistem nos diferentes objetivos dos atores políticos, e as preferências são as formas específicas pelas quais os atores buscam atingir seus interesses. Com base no indicado por Keohane e Goldstein (1993), pode-se afirmar que as preferências dos atores são diferentes por conta das distintas visões de mundo de cada um. Assim, os grupos domésticos que pleiteiam poder político são afetados cada um à sua maneira por uma mesma decisão de política exterior do Poder Executivo. Suas preferências particulares compreendem diferentes juízos sobre os mesmos acontecimentos políticos. Milner (1997) também afirma que as decisões dos líderes políticos de uma nação possuem consequências eleitorais, sendo de seu interesse optar por atitudes em consonância com as preferências da maioria dos grupos domésticos. O caso brasileiro atual se destaca essencialmente pelo uso da atuação internacional com a finalidade de angariar ganhos políticos no nível nacional. Na história brasileira, já houve momentos pontuais em que a política externa foi capaz de mobilizar e alimentar bases eleitorais, como no episódio da rejeição da Área de Livre Comércio das Américas (ALCA) (cf. BERRINGER, 2015). Contudo, a utilização de maneira sistemática e com tal intensidade da política externa brasileira para esta finalidade, como praticada a ala olavista do governo, é inédita na história brasileira.

\section{O ELEITORADO DE BOLSONARO}

A estratégia da campanha presidencial de Bolsonaro foi capaz de congregar uma multiplicidade de eleitores - que, em sua maioria, se definem como conservadores e de direita por meio de uma estratégia de comunicação que buscou segmentar diferentes informações para diferentes perfis de potenciais apoiadores (KALIL, 2018; MORETTO; ORTELLADO; SOLANO, 2017). A estratégia de segmentação de mensagens para grupos específicos conseguiu construir uma imagem de Bolsonaro capaz de assumir múltiplas formas, de acordo com as diferentes aspirações de suas bases. Longe de ser um bloco homogêneo, o eleitorado de Bolsonaro possui caráter amplamente segmentado e múltiplo (KALIL, 2018).

Observa-se, porém, uma convergência dessa diversidade na figura do "cidadão de bem", uma designação que se refere àquele que possui condutas e práticas "corretas" no âmbito da 
vida privada e que, na vida pública, considera-se e comporta-se de maneira distinta à dos chamados "corruptos" e "bandidos". Um dos principais elementos que constituem a figura do "cidadão do bem" é o discurso contra a corrupção, amplamente polissêmico, podendo se referir até mesmo a uma noção de que a corrupção é inerente à gestão pública e ao poder público. Esse discurso assume também a existência de uma "desordem" dos costumes e valores que coloca em risco uma suposta ordem familiar, amplamente ligada à prática religiosa e a condutas privadas e morais relacionadas à sexualidade. O discurso anticorrupção apresenta, ainda, uma terceira significação, associada a uma suposta confusão entre "direitos e privilégios", que se desenrola em críticas a programas sociais e de cotas (SOLANO, 2018; KALIL, 2018).

À instrumentalização da anticorrupção, se somam discursos contra o "comunismo", um conceito guarda-chuva que aglutina o temor a uma noção de esquerda política pré-associada ao petismo, ao bolivarianismo, ao "marxismo cultural", ao "Foro de São Paulo" e ao autoritarismo. Há, também, um posicionamento contra a "ideologia de gênero", que reúne discursos hostis à comunidade LGBT com acusações de pedofilia e críticas à educação social nas escolas. Destaca-se, por fim, a adoção de um discurso de demanda por "ordem" que é respaldado no medo, fruto da ineficiência da segurança pública, somado a um clamor punitivista que fundamenta propostas de redução da maioridade penal e bandeiras como "bandido bom é bandido morto" (KALIL, 2018).

Dentro do espectro do "cidadão de bem" há, portanto, um matiz que comporta diferentes eleitores de Bolsonaro. Há os que defendem uma redução drástica do Estado a partir do "anticomunismo" e do "combate à corrupção". Existem os que priorizam a preservação da estrutura familiar tradicional com base na religião diante da ameaça da "ideologia de gênero" e da "desordem de costumes e valores". Assim como há também os que, frente a um cenário que entendem como de "corrupção generalizada", buscam soluções a partir da ressignificação da história ou do espelhamento em outros países vistos como exemplos a serem seguidos.

Em estudo publicado em setembro de 2019, elaborado pelo Instituto Datafolha, elaborouse uma análise de segmentação que congrega a população brasileira em seis grupos, de acordo com o apoio de cada cidadão ao atual governo de Jair Bolsonaro. As variáveis utilizadas no estudo foram o voto declarado no segundo turno da eleição de 2018, a avaliação que o eleitor faz da atual administração e o grau de confiança nas palavras do presidente. Conforme conclui o estudo, o núcleo duro de apoiadores de Bolsonaro - denominado pela pesquisa de "bolsonaristas heavy" - consiste em 12\% da população, constituído de cidadãos que votaram em Bolsonaro no segundo turno, classificam a gestão como ótima ou boa e dizem confiar muito nas declarações do presidente. Em seguida, encontram-se os entusiastas médios, que 
correspondem a $22 \%$ dos brasileiros. Estes votaram em Bolsonaro, porém não aprovam ou não confiam plenamente nas palavras do presidente (JANONI; PAULINO, 2019).

Conforme destaca Prandi (2019), o grupo dos 12\% de "bolsonaristas heavy" não se destaca por seu tamanho, mas sim por garantir uma base social concreta e coesa que legitima as ações políticas de Bolsonaro. Segundo o autor, é razoável concluir que este grupo não retrata a diversidade da sociedade brasileira, mas é formado basicamente por homens brancos de idade madura, escolarizados e de estrato social de médio para alto. Prandi ressalta também como o estudo do Datafolha evidencia a relação entre as diferentes opções religiosas dos cidadãos e seu reflexo na questão eleitoral, visto que, entre os evangélicos neopentecostais, $23 \%$ compõem o núcleo duro de apoiadores de Bolsonaro.

Uma vez mapeados tanto os "entusiastas-médios" quanto os "bolsonaristas heavy", é profícuo explorar a plataforma discursiva da ala olavista do governo e como suas narrativas almejam satisfazer e atender às preferências dessa base eleitoral.

\section{O PROJETO CONSERVADOR NACIONAL DA ALA OLAVISTA}

O pensamento de Olavo de Carvalho acerca da política nacional possui duas premissas fundamentais: a população brasileira é acentuadamente conservadora e a democracia é um sistema em que há uma oscilação pendular entre projetos políticos diferentes. Olavo de Carvalho advoga que os Estados Unidos são o verdadeiro exemplo de democracia moderna, uma vez que apresenta oscilação pendular entre esquerda progressista e direita conservadora. Para Olavo, contudo, o conservadorismo havia sido banido da vida pública brasileira, sem espaço na mídia, nas eleições e na política. Consequentemente, até as eleições de 2018, o Brasil não vivia uma democracia, na medida em que esse eleitorado conservador era obrigado a votar "entre esquerdas", e não em um político verdadeiramente representante de suas ideias. Olavo defende ser fundamental à estabilidade e legitimidade do governo Bolsonaro que o presidente apresente um projeto político puramente conservador, voltado a seus eleitores - que, segundo Olavo, são a maior parte da população.

Esse projeto político essencialmente conservador, no âmbito da política externa, consiste em combater o globalismo. O globalismo, segundo o ideólogo, é "um conjunto de metafísicas universalizantes" (CARVALHO, 2019) que suprime as emoções e as experiências individuais, promove o epistemicídio do cristianismo e atenta contra a soberania cultural dos países e dos cidadãos ocidentais. Para ele, existem três grandes projeto globalistas contemporâneos: o islamismo, que seria o maior projeto e a maior ameaça para a Europa; o comunismo, a "ditadura 
do partido único", representado pela Rússia e pela China; e "o positivismo da sociedade administrada, a tecnocracia neoliberal do liberalismo anticristão", representado pelo expresidente norte-americano Barack Obama, Emmanuel Macron e outras elites ocidentais.

O ministro das Relações Exteriores, Ernesto Araújo (2019), por sua vez, ao assumir a pasta em janeiro deste ano, publicou na revista New Criterion um artigo intitulado "Agora falamos". Com o recurso à primeira pessoa do plural, Ernesto se refere aos indivíduos que estariam banidos da vida pública brasileira até as eleições de 2018, aqueles que se identificam propriamente como conservadores, antiglobalistas, cristãos, nacionalistas e pró-Ocidente.

Em outro artigo, intitulado "Trump e o Ocidente", publicado nos Cadernos do IPRI (Instituto de Pesquisa de Relações Internacionais), ele buscou delineou alguns desses conceitos (ARAÚJJO, 2017). Araújo apresenta uma noção de nacionalismo essencialmente concebida a partir da experiência, da emoção e do sentimento de pertencer a uma comunidade nacional que compartilha de uma mesma identidade histórica e de uma mesma cultura que, por sua vez, têm suas raízes no judaísmo cristão. Assim, o conceito de nacionalismo não comportaria a racionalidade crítica nem princípios e valores universalizantes, já que "não foi pensado pelos filósofos, [mas sim] foi sentido pelos homens diante do perigo da morte" (ARAÚJJ, 2017, p. 337). Em seu raciocínio, cabe ao Estado o papel de zelar e proteger sua comunidade nacional de ataques antinacionalistas e globalistas.

A noção de pátria (nacionalismo), então, seria uma herança grega, originada nas Guerras Médicas, que se tornaria a base do chamado "Ocidente". O mundo ocidental atual consistiria em um conjunto de nações que compartilham uma mesma identidade histórica e cultural profunda, fundamentalmente baseada na noção do nacionalismo e em valores cristãos. Ser pró-Ocidente seria reafirmar essa suposta história comum. Por outro lado, ser "globalista" é criticar e atuar contra essa narrativa histórica. Conforme enfatiza o ministro, o Ocidente é um sistema simbólico que "tem cara, nome e sangue" (ARAÚJO, 2017. p.348). Ernesto advoga que a PEB, para ser realmente brasileira, deveria estar alinhada com o que ele entende ser as demandas culturais da população brasileira. Ou seja, o Brasil deve promover sua identidade nacional no mundo defendendo seus valores em relação aos dos outros países. No caso das relações com a China, por exemplo, o Brasil, escuda o chanceler, deveria parar de priorizar o conteúdo econômico das relações e demonstrar suas divergências em relação ao autoritarismo chinês.

As ideias pró-ocidentais e nacionalistas da ala olavista estão em consonância com as de diversos outros líderes e partidos políticos espalhados pelo mundo. Um dos principais nomes relacionados a esta rede de novos conservadores é o do ex-estrategista da campanha presidencial de Donald Trump, Steve Bannon. Conforme mostrou a imprensa brasileira, a família 
Bolsonaro, especialmente Eduardo Bolsonaro, juntamente com Olavo de Carvalho e Ernesto Araújo, estabeleceu laços de amizade com Bannon, realizando encontros com certa regularidade.

Conforme destaca Alexander (2018), as ideias de Bannon e de sua rede são construídas em torno de narrativas temporais apocalípticas e de códigos binários excludentes, com uma sacralização dos patriotas e das religiões de matriz judaico-cristã. Marcos Nobre (2019), por sua vez, enfatiza como esses governos de extrema-direita, especialmente o de Bolsonaro, se caracterizam por uma postura anti-establishment e pelo uso excessivo da comunicação como forma de espalhar seu entendimento da realidade pelo restante da equipe de governo. Não por acaso, os ministérios das Relações Exteriores e da Educação são os mais cobiçados pela ala olavista.

A tática geral é simples. Não há pretensão de governar para todo mundo. Esse discurso e essa prática seriam típicos do velho mundo da velha política, que era pura enganação. Trata-se, agora, de governar para uma base social e eleitoral que não é maioria, mas que é grande o suficiente para sustentar um governo. Algo entre $30 \%$ e $40 \%$ do eleitorado. Tornar essa base fiel é fundamental para manter o poder (NOBRE, 2018).

Lá realizou visita à CIA e se encontrou com Donald Trump para discutir as questões do governo venezuelano de Nicolás Maduro e de um possível apoio norte-americano à entrada do Brasil na OCDE. Além disso, as nações firmaram o acordo de cessão da Base de Alcântara. Os presidentes também realizaram um pronunciamento em conjunto enfatizando a convergência de valores (Deus, Pátria e Família) entre as nações, sendo que Bolsonaro afirmou-se como o primeiro presidente brasileiro não antiamericano em décadas (BRASIL, 2019). Como gesto para enfatizar a nova aproximação entre os dois países, Trump concedeu ao Brasil o status de "major non-NATO ally", algo nunca reivindicado pelo Brasil.

Posteriormente, em episódio envolvendo orientação presidencial para que a Petrobrás não abastecesse navios de bandeira iraniana que carregavam milho importado do Brasil para o Irã, Bolsonaro viria a afirmar à imprensa que "nós estamos alinhados à política deles [EUA]. Então faremos o que tem de fazer (...) eu particularmente estou me aproximando cada vez mais do Trump" (BRASIL, 2019), referindo-se à política norte-americana de sanções ao Irã. Há de se destacar que o Irã consiste no maior importador de milho do Brasil, além de ser também um dos maiores compradores de nossa soja e carne bovina.

Outros exemplos a serem destacados são os posicionamentos, em consonância com o governo Trump e com o nacionalismo antiglobalista, de negacionismo dos problemas ambientais e de reprovação dos Direitos Humanos. Estas posições implicaram na desistência brasileira em sediar a Conferência do Clima da ONU em 2019, bem como no abandono, por parte do Brasil, do Pacto Global para Migração da ONU no início deste ano e levaram a controvérsias com chefes de 
Estado europeus em torno da preocupação, justificado ou não, com a Floresta Amazônia (AMARAL, 2019; DEUTSCHE WELLE, 2019).

Tal postura com relação aos EUA tem sido amplamente explorada desde a campanha presidencial - sendo o episódio da continência prestada à bandeira norte-americana seu momento mais marcante - e continua a ser largamente utilizada pelo presidente, orientado pela ala olavista do governo, por meio de sua política externa de alinhamento ideológico aos norteamericanos. Neste contexto, encontra-se o episódio mais recente da indicação de Eduardo Bolsonaro para Embaixador brasileiro em Washington, o que visa fortalecer os laços entre os governos Bolsonaro e Trump.

Em todos os episódios supracitados, observa-se, por parte da "ala olavista", a mobilização do plano internacional para o favorecimento simbólico e eleitoral no plano nacional. Estas ações de política externa buscaram satisfizer a figura do "cidadão do bem" eleitor de Bolsonaro, na medida em que ensaiaram uma aproximação de amizade com um país visto como exemplo de ordem, de luta contra o "comunismo" e o "islamismo", e de valores e costumes corretos.

A incoerência com força apareceu com relação à China. Nesse caso houve um ensaio de alinhamento com os EUA com uma postura declaradamente anti-China que logo foi superado pela realidade dos interesses econômicos e comerciais. Ao mesmo tempo ficou claro que o declarado alinhamento ideológico com os EUA não gerou benefícios econômicos concretos. Essa incoerência, porém, não interfere no diálogo do Bolsonaro com sua base em torno de um posicionamento pró-americano. E, nessa narrativa, a política dos governos do PT é caracterizada como antiamericana para marcar o terreno da disputa.

\subsection{ISRAEL E O JUDAÍSMO CRISTÃO}

Bolsonaro, antes mesmo de se candidatar a presidente, trabalhou para associar sua imagem à do Estado de Israel, seja realizando declarações de apoio a Benjamin Netanyahu ou se benzendo no rio Jordão. Uma vez presidente, anunciou parcerias com a nação judaica e a colocou como prioritária na sua agenda de viagens internacionais (foi sua terceira visita externa) a primeira visita foi aos EUA, e a segunda ao Chile -, na véspera da reeleição de Netanyahu (OLIVEIRA, 2018).

Em harmonia com a política externa trumpista, Bolsonaro havia anunciado, já durante a campanha presidencial, que transferiria a embaixada brasileira de Tel-Aviv para Jerusalém, numa forte afronta simbólica à Palestina e à Liga Árabe (SCHUTTE, PIDONE e CORREA, 2019). Essas e outras ações da gestão Bolsonaro em relação a Israel destoam tanto do posicionamento dos 
militares quanto das elites econômicas, mas respondem aos anseios de seu eleitorado evangélico, que, por conta da doutrina do dispensacionalismo ${ }^{13}$, ambiciona a glorificação e a preservação do Estado de Israel frente aos seus conflitos regionais. Trata-se de um "sionismo evangélico", uma posição baseada em profecias bíblicas que assumem esse povo como eleito de Deus. Jerusalém é a terra do povo de Deus, que, portanto, precisa ser defendida dos inimigos.

Para o sionismo evangélico, a transferência da embaixada brasileira de Tel Aviv para Jerusalém é um objetivo central, tendo sido tema presente durante toda a campanha eleitoral. Isso se deu inclusive nas declarações do Bolsonaro no início de seu governo.

Ademais, o Estado de Israel, para a ala olavista, representa uma frente fundamental contra o avanço do islamismo, visto como o globalismo mais perigoso para o Ocidente. Dessa forma, há uma sintonia entre as formulações da ala olavista e parte do eleitorado de Bolsonaro, ensejando uma profícua mobilização da política externa para ganhos domésticos. Para tanto, o alinhamento geopolítico do Brasil e dos EUA a Israel se faz mais do que óbvio e necessário.

Somando-se a esses fatores, outro indicador do renovado interesse por Israel é o expressivo aumento do turismo de brasileiros para aquele país, que registrou entre 2017 e 2019 um aumento de 22,1\%, atingindo o recorde de quase 70 mil visitantes neste ano. Pouco tempo antes, em dezembro de 2018, o grupo LATAM Airlines inaugurou uma rota direta entre os dois países (São Paulo- Tel Aviv).

A declarada aliança com o Estado de Israel convive, porém, com a realidade de interesses econômicos e comerciais junto aos países árabes. E, ainda em 2019, Bolsonaro visitou as monarquias conservadoras na península arábica, aliados de longa data dos EUA.

A contradição entre o desejo e a realidade resultou na decisão salomônica de instalar um escritório em Jerusalém para a promoção do comércio, investimentos, tecnologia e inovação, ação coordenada pelo Ministério das Relações Exteriores. A representação diplomática, no entanto, acabou sendo descartada. O recuo do governo foi explicado, porém, pela dificuldade de fazer a alteração em curto tempo e houve certa insistência em afirmar que tal proposta não foi abandonada. Assim, se mantém o diálogo com a base eleitoral do presidente, em particular a ala evangélica, o excepcionalismo da relação com Israel e o desejo declarado de seguir o exemplo dos EUA na instalação da Embaixada em Jerusalém. Ao mesmo tempo, a política dos governos anteriores é caracterizada, desde a campanha eleitoral, como anti-israelita, totalmente favorável à causa palestina, o que enfatiza a disputa política em torno da questão.

\footnotetext{
${ }^{13} \mathrm{O}$ dispensacionalismo é uma doutrina teológica cristã que consiste na crença de que a existência do Estado de Israel é uma das pré-condições fundamentais para o retorno de Jesus Cristo. A figura do rei Davi tem uma importância fundamental nisso, porque foi ele que escolheu, há três mil anos, Jerusalém como capital de Israel, estabelecendo seus limites, nos quais hoje o movimento mais conservador e fundamentalista em Israel pretende estabelecer os assentamentos.
} 


\subsection{VENEZUELA E O ANTICOMUNISMO}

Durante a campanha à presidência, Bolsonaro se posicionou como claro oponente do governo venezuelano, liderado por Nicolás Maduro, criticando-o como "bolivarianista", "comunista". A atual situação macroeconômica da Venezuela, por sua vez, é um impeditivo para a expansão das relações comerciais com o Brasil, que no passado foram extremamente superavitárias. Contudo, uma possível situação de guerra apenas agravaria essas dificuldades. Assim, o posicionamento beligerante explícito contra a Venezuela foi aceito até o momento em que o discurso de guerra ameaçou se concretizar, situação em que a ala militar e diversas outras alas internas do governo passaram a atuar de forma a amenizar as possibilidades de conflito armado.

Simultaneamente ao discurso geopolítico hostil à Venezuela, a ala olavista e seus correligionários projetam o discurso acerca da criminalização da política do Banco Nacional do Desenvolvimento Econômico e Social (BNDES) de concessão de crédito às empresas brasileiras, uma vez que essa política de desenvolvimento é concebida por esse grupo como um mecanismo de corrupção endêmica e de transferência de recursos do contribuinte brasileiro para países caracterizados como "comunistas" - em particular Venezuela e Cuba.

Assim, verifica-se que os fins da postura de Bolsonaro são de caráter muito mais simbólicos do que materiais. Ao combater a Venezuela desta maneira, Bolsonaro mantém seu eleitorado conservador, "anticomunista" e "antipetista" mobilizado, além de também reforçar seu alinhamento ideológico com Washington e o trumpismo. E isso também é algo valorizado pelo eleitor que compreende, como mencionado acima, os EUA como uma nação exemplar e inconteste a ser seguida. Assim, uma política externa hostil à Venezuela de Maduro suscita um "jogo de dois níveis", na medida em que o plano internacional fornece possibilidades discursivas de alta adesão para plano doméstico eleitoral.

\subsection{AMAZÔNIA E A PROJEÇÃO INTERNACIONAL DA POLÍTICA AMBIENTAL}

Amplamente noticiada na época pela mídia nacional e internacional, no dia 19 de agosto de 2019, ainda durante a tarde, a cidade de São Paulo foi tomada por nuvens escuras que assustaram a população paulista. Conforme alguns institutos de pesquisa em meteorologia, tal evento teve relação direta com as queimadas que ocorrem na Amazônia. Em pronunciamento sobre o assunto, Bolsonaro rotulou a onda de queimadas ${ }^{14}$ na Amazônia de "criminosa" e atribuiu

\footnotetext{
${ }^{14}$ Desde janeiro de 2019 até o dia 20 de agosto de 2019 foram registrados 74155 focos de incêndio florestal na Amazônia, uma alta de $84 \%$ em relação ao mesmo período do ano anterior, consistindo no
} 
a culpa destas as Organizações não-Governamentais (ONGs) que atuam na Floresta realizando ações de proteção ambiental.

O episódio da escuridão no céu de São Paulo somado às declarações do presidente operaram como um gatilho para a opinião pública internacional de caráter pró-ambientalista (OLIVEIRA, 2019). Assim, dois dias depois, a hashtag \#PrayforAmazonas ocupava o primeiro lugar dos trending topics mundiais da rede social Twitter, e diversas figuras públicas, como as cantoras Madonna e Shakira, o ator Leonardo DiCaprio, e o futebolista Cristiano Ronaldo, se pronunciaram em suas redes sociais manifestando preocupação com a devastação da Amazônia. Além disso, ao longo da semana, revistas e jornais internacionais renomados como os norte-americanos The New York Times e National Geographic, o britânico The Guardian, e o alemão Deutsche Welle, produziram artigos e notícias dando destaque às queimadas e às respostas insuficientes do presidente brasileiro (MARTUCCI, 2019).

Diante de tal repercussão, sob a iniciativa do presidente francês Emmanuel Macron ${ }^{15}$, a reunião de cúpula do G7, realizada nos dias 24 e 25 de agosto de 2019, chegou ao acordo de liberar UR \$ 22 milhões para auxiliar na proteção da Amazônia. Contudo, Bolsonaro afirmou que só aceitaria a ajuda do G7 caso Macron "retirasse insultos" que havia feito ao presidente brasileiro (BBC NEWS BRASIL, 2019). Além disso, durante a fala de anúncio da ajuda financeira, Macron afirmou que o debate sobre a internacionalização jurídica da Amazônia estava em aberto. Esse posicionamento de Macron ensejou que Bolsonaro o respondesse acusando a "mentalidade colonialista" de tais medidas, advogando que o presidente francês estaria atentando contra a soberania brasileira e instrumentalizando uma questão interna do Brasil para ganhos políticos pessoais (O GLOBO, 2019b). Esse recurso retórico de Bolsonaro permitiu uma ressignificação da situação internacional como "um atentado globalista", ensejando então a mobilização de seu apoio do eleitorado tanto para sua postura internacional quanto para sua postura doméstica relacionada aos desmatamentos da Amazônia.

Contudo, a crise internacional instalada acerca das queimadas amazônicas, a despeito de sua ressignificação servir para reforçar o discurso da ala olavista e, aparentemente, beneficiar as elites econômicas agroexportadoras - na medida em que as permite que explorem mais as terras cultiváveis da Amazônia -, reforçou a tensão com interesses dessas últimas. Não apenas pelas eventuais sanções econômicas insinuadas por Macron, mas, principalmente, pelo risco de não ratificação tanto no parlamento europeu quanto nos dos respectivos países constituintes, do

número mais alto desde quando se começaram os registros realizados pelo Instituto Nacional de Pesquisa Espacial (INPE) (BARBOSA, 2019).

${ }^{15} \mathrm{O}$ presidente francês Emmanuel Macron, acusou Bolsonaro de mentir sobre compromissos ambientais assumidos durante o encontro do G20 em Osaka. Além disso, o presidente francês, em seu Twitter, declarou que a situação da Amazônia representava uma "crise internacional". Tal publicação foi endossada pelo presidente canadense, Justin Trudeau. 
recentemente assinado acordo Mercosul-União Europeia (O GLOBO, 2019a). Esses riscos já haviam sido denunciados por alguns representantes canônicos do agronegócio brasileiro, que se manifestaram publicamente contra a postura do Bolsonaro em relação à política ambiental (ZAIA, 2019), acusando-a, inclusive, de uma postura "anti-mercado" (ABREU, 2019). Nesse sentido, a Amazônia, assim como toda a projeção internacional da política ambiental do Bolsonaro, consiste numa questão de tensão entre os grupos participantes do governo. Não há um recuo claro, uma vez que as acusações contra as ONGs internacionais continuam e com grande ressonância nas redes sociais dos apoiadores do Bolsonaro. A crítica à política do governo com relação ao meio ambiente é projetada como sendo anti-nacionalista. Ao mesmo tempo tenta se amenizar o tom e demonstrar pragmatismo diante os apelos dos setores econômicos prejudicados.

\subsection{O INTERNACIONAL COMO PLATAFORMA SIMBÓLICA}

Nas situações internacionais que não representam interesses diretos das elites econômicas nacionais, a ala olavista é desinibida de se propagar e utiliza essas oportunidades para capitalizar simbolicamente e reforçar a agenda cultural de seus eleitores, mantendo-os permanentemente mobilizados. Em outras palavras, sob uma noção adaptada do "Jogo de Dois Níveis", a ala olavista ancora no plano internacional discursos capazes de fortalecer a posição interna de Bolsonaro em relação a uma parcela relevante de seus eleitores.

O discurso do presidente Jair Bolsonaro na abertura da Assembleia da ONU de 2019 manifesta bem essa dinâmica. Numa fala visivelmente hermética, Bolsonaro enfatizou diversas pautas de seus eleitores, como a defesa da família heterossexual, do cristianismo, da soberania isolacionista, da identidade do ocidente, assim como também justificou o golpe militar de 1964 como uma defesa nacional contra a influência cubana e projetou as aversões ao socialismo e ao ambientalismo (G1 GLOBO, 2019). Soma-se a esse evento a iniciativa de incluir menções à família e eliminar menções à gênero, LGBT, pobreza e tortura na candidatura ao conselho de Direitos Humanos da ONU (DUCHIADE, 2019a) e o recente apoio dos votos brasileiro na retirada de diversas recomendações deste conselho acerca de direitos sexuais (DUCHIADE, 2019b). Todas essas posições se sintonizam com as pautas domésticas do eleitorado de Bolsonaro. A ONU, nesse sentido, tem se provado uma plataforma profícua para que a ala olavista usufrua da política externa para mobilizar o eleitorado. É também nessa arena que não há aparentemente custos em romper com a tradição diplomática brasileira e se isolar do voto sul-americano ao apoiar o bloqueio a Cuba e seguir o voto dos EUA em não condenar Israel por sua política de promover assentamentos na Cisjordânia. 


\section{CONSIDERAÇÕES FINAIS}

Na história brasileira, episódios nos quais uma pauta de política externa foi capaz de mobilizar e alimentar uma base eleitoral são raros, sendo o caso da rejeição da ALCA um dos mais notórios. As análises das manifestações e dos discursos dos eleitores de Bolsonaro denotam uma grande presença, para além das pautas voltadas à política nacional, de práticas e discursos voltados às questões internacionais de política externa, como a presença das bandeiras estadunidenses e israelenses nas mobilizações da sua base de apoio ou, por exemplo, os clamores de "vai pra Cuba!" e "o Brasil não vai virar uma Venezuela!". O uso desses motes tem como consequência imediata a mobilização da sua base eleitoral contra o Partido Trabalhista e outros grupos políticos que discordem da plataforma política de Bolsonaro.

Contudo, a mescla de grupos de interesses que compõem o governo Bolsonaro ensejam, no seu primeiro ano, uma política externa brasileira repleta de contradições e, supostamente, incoerências. Enquanto que parcelas do governo, representadas pelos Ministérios da Economia, Agricultura, Minas e Energia, a vice-presidência e os setores da burocracia como o Banco Central, aspiraram uma política externa economicamente pragmática, que preze pelos respectivos interesses materiais das elites econômicas, a ala olavista, pelo seu receio antiglobalista, inclinavam-se a um alinhamento com a política trumpista que tensiona com, por exemplo, as relações econômico-comerciais brasileiras com a China e os países árabes, assim como quase levam o Brasil a um conflito armado com a Venezuela.

Assim, a política externa de Bolsonaro, quando predominada pela ala olavista, ao se harmonizar com as preferências do seu eleitorado, consegue, ao mesmo tempo, deixar sua base eleitoral mobilizada e munir simbolicamente seus correligionários na guerra cultural nacional. Os exemplos supracitados da atuação da ala olavista na ONU ilustram bem essa dinâmica, de forma que Bolsonaro tentou usufruir da sua posição no âmbito internacional para angariar prestígio para sua posição no âmbito doméstico. Essa dinâmica se enquadra em um dos casos derivados do Jogo de Dois níveis adaptado, na medida em que Bolsonaro, na figura de mediador entre o cenário doméstico e o internacional, canaliza seus recursos disponíveis - materiais e, principalmente, simbólicos - em ambos os níveis para, no seu caso específico, favorecer sua situação doméstica.

Objetivar teoricamente o uso da política externa para favorecer a situação eleitoral do governo de Bolsonaro fornece subsídios para compreender o processo de condução das Relações Exteriores, como resultado de um processo essencialmente político. Nesse sentido, essa perspectiva compreende que o conteúdo da inserção internacional de um país não se deriva, necessariamente, dos anseios das elites econômicas - leitura que tende a incorrer num 
determinismo analítico economicista -, mas que é a resultante da dinâmica política interna em que o governo está submergido. Esse instrumental teórico permite compreender que a Política Externa do Bolsonaro não é despida de racionalidade por não se adequar ao tradicional pragmatismo econômico da PEB, uma vez que sua racionalidade reside na ambição de fortalecer seu apoio eleitoral e a guerra cultural doméstica. Ao mesmo, ela é estruturalmente incoerente por encontrar seu limite nos interesses econômicos.

* Artigo recebido em 23 de outubro de 2019, aprovado em 09 de dezembro de 2019.

\section{REFERENCIAS}

ABREU, Katia. Katia Abreu: 'Produtores que estão alegres hoje vão chorar amanhã'. [Entrevista concedida a] Anne Warth e Adriana Fernandes. O Estado de São Paulo. Disponível em: $<$ https://politica.estadao.com.br/noticias/geral,produtores-que-estao-alegres-hoje-vao-choraramanha,70002965256>. Acesso em: 15 de outubro de 2019.

ALEXANDER, Jeffrey C.. Vociferando Contra o lluminismo: a Ideologia de Steve Bannon.. Sociol. Antropol., Rio de Janeiro, v. 8, n.3, p.1009-1023, Dezembro, 2018. Disponível em: $<$ http://www.scielo.br/scielo.php?script=sci_arttext\&pid=S2238-

$38752018000301009 \&$ Ing=en\&nrm=iso $>$. Acesso em 20 de setembro de 2019.

AMARAL, Luciana. Bolsonaro sobre Noruega: "Não é aquela que mata baleia e explora petróleo?". Uol, 2019. Disponível em: <https://noticias.uol.com.br/meio-ambiente/ultimasnoticias/redacao/2019/08/15/bolsonaro-sobre-noruega-nao-e-aquela-que-mata-baleia-eexplora-petroleo.htm>. Acesso em: 02 de agosto de 2019.

ARAÚJO, Ernesto. Agora Falamos. The New Criterion. Vol. 37, No. 10 / June 2019. Disponível em: $<$ https://www.newcriterion.com/issues/2019/1/agora-falamos>. Acesso em 23 de Junho de 2019.

ARAÚJO, Ernesto. Aula magna do ministro de estado das relações exteriores, embaixador Ernesto Araújo, no Instituto Rio Branco, em 11/03/19. Brasília. Disponível em: <http://funag.gov.br/index.php/pt-br/component/content/article?id=2912>. Acesso em: 27 de julho de 2019.

ARAÚJO, Ernesto. Trump e o Ocidente. Cadernos de Política Exterior. Instituto de Pesquisa de Relações Internacionais. v. 3, n. 6 (dez. 2017). Brasília: FUNAG, 2015.

BARBOSA, Vanessa. Inferno na floresta: o que sabemos sobre os incêndios na Amazônia. Disponível em: <https://exame.abril.com.br/brasil/inferno-na-floresta-o-que-sabemos-sobre-osincendios-na-amazonia/>. Acesso em 13 de outubro de 2019. 
BBC NEWS BRASIL. 'Macron tem que retirar os insultos': 10 momentos chave da crise por fogo na Amazônia. Disponível em: <https://www.bbc.com/portuguese/internacional-49483220>. Acesso em: 14 de outubro de 2019.

BERRINGER, Tatiana. A burguesia brasileira e a política externa dos governos FHC e Lula. Curitiba: Appris, 2015.

BRASIL. Presidente (2019: Jair Messias Bolsonaro). Declaração à imprensa sobre o caso dos navios iranianos. Disponível em: <https://www1.folha.uol.com.br/mundo/2019/07/estamosalinhados-a-politica-dos-eua-diz-bolsonaro-sobre-navios-iranianos.shtml>. Acesso em: 01 de agosto de 2019.

BRASIL. Presidente (2019: Jair Messias Bolsonaro). Discurso por ocasião de visita ao Presidente dos Estados Unidos da América. Washington, 19 mar. 2019. Disponível em: <https://www.youtube.com/watch?v=zpizXj_nQ00>. Acesso em: 2 de dezembro de 2019.

BRASIL. Presidente (2019: Jair Messias Bolsonaro). Entrevista à rádio Jovem Pan acerca das relações entre Brasil e Venezuela. Disponível em: <https://www.correiodobrasil.com.br/bolsonarotrump-invadir-venezuela-brasil-junto/>. Acesso em: 5 de setembro de 2019.

CARTA CAPITAL. Ernesto Araújo: "O conservador é o menos preconceituoso que existe". Carta Capital, São Paulo. Disponível em: <https://www.cartacapital.com.br/politica/ernesto-araujo-oconservador-e-o-menos-preconceituoso-que-existe/>. Acesso em: 15 de outubro de 2019.

CARVALHO, Olavo de. Olavo de Carvalho sobre os três projetos globalistas existentes e fontes intelectuais remotas. Youtube, 18 jul. 2019. Disponível em <https://www.youtube.com/watch?v=R-wxblFVWbY>. Acesso em: 13/10/2019

DEUTSCHE WELLE. "Pegue essa grana e refloreste a Alemanha", diz Bolsonaro a Merkel. Deutsche Welle, 2019. Disponível em: <https://www.dw.com/pt-br/pegue-essa-grana-erefloreste-a-alemanha-diz-bolsonaro-a-merkel/a-50035007>. Acesso em: 02 de agosto de 2019.

DUCHIADE, André. Brasil acompanha países islâmicos em votações sobre direitos das mulheres e sexuais na ONU. O Globo, 2019b. Disponível em: <https://oglobo.globo.com/mundo/brasilacompanha-paises-islamicos-em-votacoes-sobre-direitos-das-mulheres-sexuais-na-onu23800730 > Acesso em: 13 de outubro de 2019.

DUCHIADE, André. Governo Bolsonaro inclui família e elimina menções a gênero, pobreza e tortura em candidatura na ONU. O Globo, 2019a. Disponível em: $<$ https://oglobo.globo.com/mundo/governo-bolsonaro-inclui-familia-elimina-mencoes-generopobreza-tortura-em-candidatura-na-onu-23798604>. Acesso em: 13 de outubro de 2019.

ELER, Guilherme. Afinal, a fumaça que deixou São Paulo no escuro veio mesmo da Amazônia? Super Interessante. Disponível em: <https://super.abril.com.br/ciencia/afinal-a-fumaca-quedeixou-sao-paulo-no-escuro-veio-mesmo-da-amazonia/>. Acesso em: 14 de outubro de 2019.

ÉPOCA NEGÓCIOS. Bolsonaro recua sobre embaixada e anuncia escritório comercial em Jerusalém. Globo, $2019 . \quad$ Disponível em: <https://epocanegocios.globo.com/Mundo/noticia/2019/03/bolsonaro-anuncia-escritorio-dobrasil-em-jerusalem.html> Acesso em: 01 de agosto de 2019. 
G1 GLOBO. Parlamento da Áustria rejeita acordo UE-Mercosul. São Paulo. 19 de Setembro de 2019. 2019a. Disponível em: <https://g1.globo.com/economia/noticia/2019/09/19/parlamento-daaustria-rejeita-acordo-ue-mercosul.ghtml>. Acesso em 29 de Setembro de 2019.

G1 GLOBO. Veja a íntegra do discurso de bolsonaro na abertura da Assembleia Geral da ONU. São Paulo. 24 de Setembro de 2019. 2019b. Disponível em: <https://g1.globo.com/mundo/noticia/2019/09/24/veja-a-integra-do-discurso-de-bolsonaro-naabertura-da-assembleia-geral-da-onu.ghtml>. Acesso em 29 de Setembro de 2019.

GALLEGO, Esther Solano; ORTELLADO, Pablo; RIBEIRO, Marcio Moretto. Guerras culturais e populismo antipetista nas manifestações por apoio à Operação Lava Jato e contra a reforma de previdência. Em Debate (Belo Horizonte), Belo Horizonte, v. 9, n. 2, p. 35-45, 2017. Disponível em: <http://opiniaopublica.ufmg.br/site/files/artigo/7.pdf >.

KALIL, Isabela O. Quem São e No Que Acreditam Os Eleitores De Jair Bolsonaro. Fundação Escola de Sociologia e Política de São Paulo. Outubro, 2018.

KATZENSTEIN, Peter J. International Relations and Domestic Structures: Foreign Economic Policies of Advanced Industrial States. International Organization, v. 30, n. 1, p. 1-45, 1976.

KEOHANE, R. O; GOLDSTEIN, J. Ideas and Foreign Policy: An Analytical Framework. In: Keohane, R. O; Goldstein, J. Ideas And Foreign Policy. Beliefs, Institutions, and Political Change. New York: Cornell University Press,p. 3-30. 1993.

MARTUCCI, Mariana. O que diz a imprensa internacional sobre as queimadas na Amazônia. EXAME. Disponível em: <https://exame.abril.com.br/brasil/o-que-diz-a-imprensa-internacionalsobre-as-queimadas-na-amazonia/>. Acesso em: 14 de outubro de 2019.

MILNER, H. V. Interests, institutions and information: domestic politics and international politics. Princeton: Princeton University Press, 1997.

NOBRE, Marcos. A Revolta Conservadora. Revista Piauí, edição 147, dezembro, 2018. Disponível em: <https://piaui.folha.uol.com.br/materia/a-revolta-conservadora/>. Acesso em: 20 de setembro de 2019.

NOBRE, Marcos. O Caos Como Método. Revista Piauí, edição 151, abril, 2019. Disponível em: $<$ https://piaui.folha.uol.com.br/materia/o-caos-como-metodo/>. Acesso em: 20 de setembro de 2019.

O GLOBO. Bolsonaro diz que Macron evoca 'mentalidade colonialista' ao tratar de queimadas no Brasil. Jornal O Globo. 22 de agosto de 2019. Disponível em: $<$ https://oglobo.globo.com/sociedade/bolsonaro-diz-que-macron-evoca-mentalidadecolonialista-ao-tratar-de-queimadas-no-brasil-23896876> Acesso em: 15 de setembro de 2019.

OLIVEIRA, Joana. Onda de incêndios na Amazônia sobe e Governo admite descontrole "criminoso". El País. Eisponível em: $<$ https://brasil.elpais.com/brasil/2019/08/21/politica/1566407148_180887.html>. Acesso em: 14 de outubro de 2019.

OLIVEIRA, Regiane. Batismo no rio Jordão, empresários e promessas vazias: como Bolsonaro construiu a imagem de "amigo de Israel". 2018 Disponível em: <https://brasil.elpais.com/brasil/2018/10/23/politica/1540319360_061442.htm>. Acesso em: 01 de agosto de 2019. 
PAULINO, Mauro. JANONI, Alessandro. Núcleo duro de apoio a Bolsonaro é de $12 \%$ da população, aponta Datafolha. Folha de São Paulo, 2019. Disponível em: $<$ https://www1.folha.uol.com.br/poder/2019/09/nucleo-duro-de-apoio-a-bolsonaro-e-de-12-dapopulacao-aponta-datafolha.shtml>. Acesso em: 07 de setembro de 2019.

PENNAFORT, Roberta. "Países podem comprar no Brasil mas não o Brasil", diz Bolsonaro. O Estado de São Paulo, $2018 . \quad$ Disponível em: $<$ https://economia.estadao.com.br/noticias/geral,paises-podem-comprar-no-brasil-mas-naocomprar-o-brasil-diz-bolsonaro,70002587504> Acesso em: 05 de agosto de 2019.

PRANDI, Reginaldo. Os $12 \%$ do presidente - em que lugar da sociedade habita o bolsonarista convicto? Jornal da USP, 2019. Disponível em: <https://jornal.usp.br/artigos/os-12-dopresidente-em-que-lugar-da-sociedade-habita-o-bolsonarista-convicto/>. Acesso em: 14 de setembro de 2019.

PUTNAM, Robert. Diplomacy and Domestic Politics: The Logic of Two-Level Games. International Organization. Vol. 42, No. 3, p. 427-460, 1988.

SCHUTTE, Giorgio R; PIDONE, Beatriz; CORREA, Matheus.. Uma nova prioridade para a política externa: Israel. Observatório de Política Externa Brasileira da UFABC. Disponível em: <http://opeb.org/2019/03/17/uma-nova-prioridade-na-politica-externa-israel/>. Acesso em: 2 de dezembro de 2019.

SOLANO, Esther. Crise da democracia e extremismos de direita. São Paulo: Fundação Friedrich Ebert, 2018. Disponível em: http://library.fes.de/pdffiles/bueros/brasilien/14508.pdf. Acesso em: 18 de Maio de 2019.

TARGA, Leandro. Os diplomatas brasileiros sob a perspectiva relacional: o campo dos diplomatas e o campo político. Tese (Doutorado em Ciência Política) - Programa de Pós-Graduação em Ciência Política da Universidade Federal de São Carlos, São Carlos, 2017.

VEJA. Ernesto Araújo: 'Dizem que somos trumpistas, o que é um pouco verdade'. Veja, 2019. Disponível em: <https://veja.abril.com.br/mundo/ernesto-araujo-dizem-que-somos-trumpistas-oque-e-um-pouco-verdade/>. Acesso em: 01 de agosto de 2019.

ZAIA, Cristiano. "Retórica do governo levará agronegócio à estaca zero", diz Blairo. Valor Econômico, São Paulo, 2019. 15 agosto de 2019 Acesso 15 de outubro de 2019. Disponível em:<https://valor.globo.com/brasil/noticia/2019/08/15/retorica-do-governo-levara-agronegocioa-estaca-zero-diz-blairo.ghtml>. 